Коркин Роман Иванович

старший преподаватель кафедры антикризисного управления и финансового оздоровления

Международного банковского института

\section{ФИНАНСОВАЯ ГРАМОТНОСТЬ НАСЕЛЕНИЯ КАК ФАКТОР ОБЕСПЕЧЕНИЯ ЭКОНОМИЧЕСКОЙ БЕЗОПАСНОСТИ ГОСУДАРСТВА}

\begin{abstract}
Аннотация:
В настоящей статье уделено особое внимание финансовой грамотности населения Российской Федерации в связи с принятием стратегической концепции государства. Сделан анализ предшествующей Стратегии повышения финансовой грамотности. Освещены основные положения вновь разработанной Cтратегии повышения финансовой грамотности населения в России. Изучен ряд конкретных органов государственной власти и других участников, которые ответственны или заинтересованы в реализации рассматриваемых задач. Автор исследует факторы и критерии, влияющие на финансовое положение граждан в нашей стране. Проанализирован зарубежный и отечественный опыт повышения финансовой грамотности. Сделан вывод о низком уровне знаний, практических навыков и установок граждан в сфере личных финансов. Приведены и изучены понятия и инструменты повышения финансовой грамотности населения.
\end{abstract}

Ключевые слова:

финансы, доход, деньги, финансовая политика, финансовая грамотность, экономика, государство, личный бюджет
Korkin Roman Ivanovich

Senior Lecturer, Department of Crisis Management and Financial Recovery, International Banking Institute, St. Petersburg

\section{FINANCIAL LITERACY AS A FACTOR OF STATE ECONOMIC SECURITY}

Summary:

The research focuses on the financial literacy in the Russian Federation due to the state strategic concept adopted in this regard. The preceding strategy for improving financial literacy in Russia and the new one are analyzed. The paper examines a number of specific public authorities and other actors who are responsible for or interested in the implementation of the strategic tasks. The study reviews the factors and criteria affecting the financial situation of citizens in this country. Russian and international practices for improving financial literacy are considered. The research proves that there is a low level of knowledge, practical skills and attitudes of the citizens in the field of personal finance. The author provides the concepts and tools to improve financial literacy in Russia.

Стремительные изменения экономической ситуации в Российской Федерации на протяжении последних лет определили ряд изменений во внутренней и внешней политике руководства, в том числе фринансовой политике государства, направленной на повышение финансовой грамотности населения. Осуществление данной политики, с одной стороны, закладывает основу стабильного развития российской экономики в целом, с другой - определяет умение и способность достигать личного финансового успеха, повышает благосостояние отдельного человека. В качестве катализаторов таких трансформаций стоит выделить экономический кризис, в силу которого у граждан увеличивается необходимость учета и распределения личных фринансов при росте цен, снижение стоимости накоплений, «урезание» зарплаты, отсутствие знаний в области финансов или нежелание их получать, резкое изменение курса национальной валюты по отношению к иностранной и др.

В рамках политики, направленной на повышение уровня финансовой грамотности, федеральные органы государственной власти в 2011 г. приняли концепцию и запустили соответствующий проект «Содействие повышению уровня финансовой грамотности населения и развитию финансового образования в Российской Федерации» [1]. Данный проект был рассчитан на 5 лет. В настоящее время по итогам реализованной программы органами власти, куда входят представители Минфина РФ, Центробанка РФ, Минобрнауки РФ, Пенсионного фонда РФ, Роспотребнадзора, разработан и подготовлен к принятию проект национальной стратегии повышения финансовой грамотности, рассчитанный на 2017-2023 гг. (далее - Стратегия) [2].

В указанном документе находят отражение приоритеты и методы эффективного достижения целей и решения проблем в сфере государственного управления финансовой грамотностью населения, способы создания системы образования и обучения управлению личными финансами и информирования в области защиты прав потребителей финансовых услуг на среднесрочный период. В Стратегии повышение финансовой грамотности населения рассматривается как один из основополагающих фракторов увеличения конкурентоспособности российской экономики. 
Хотя в данном направлении предпринимаются конкретные шаги, в том числе со стороны государства, уровень финансовой культуры остается крайне низким и требует скоординированной и систематической работы.

Вопросы учета личных фринансов волновали общество на протяжении многих веков. Указанные этапы описал Ф. Модильяни - американский экономист, лауреат Нобелевской премии 1985 г. «за анализ финансовых рынков и поведения людей в отношении сбережений». Его концепция базируется на утверждении, что человек стремится поддерживать постоянным уровень потребления, несмотря на колебание дохода. Формула Ф. Модильяни звучит так: «Молодые сберегают, старые растрачивают» [3]. На наш взгляд, данное утверждение не совсем верно, поскольку на практике отмечено и другое поведение разных социальных слоев: пожилые люди могут сберегать и накапливать средства, а молодежь - пренебрежительно относиться к ним и растрачивать «впустую».

На современном этапе выделяют следующие причины низкой финансовой грамотности среди россиян: отсутствие навыков по составлению личного финансового плана, формированию денежных резервов на случай форс-мажорных обстоятельств [4]; недостаточный уровень платежной дисциплины и надлежащего исполнения обязательств, вытекающих из договоров с кредитными организациями [5]. В то же время заемщики, которые попали в сложную финансовую ситуацию из-за образовавшихся долгов, возложили ответственность и «обвинили в бедах» внешние обстоятельства - государство, работодателя, мировой кризис, экономические санкции, изменение курса иностранной валюты и др., а не собственные установки обращения с личными финансами.

Низкая фринансовая грамотность россиян обусловлена двумя основными проблемами, которые присущи нашему обществу. Первая связана с отсутствием эффрективной модели обучения финансовой грамотности в образовательных учреждениях разного уровня, дефицитом или отсутствием понятных и доступных программ по обучению учету личных фринансов (это особенно актуально для школ, ссузов, вузов), недостатком квалифицированных педагогов, обучающих финансовой грамотности.

Вторая проблема имеет комплексный характер и представлена следующими элементами:

- недостатком законодательного и правового обеспечения, т. е. отсутствием нормативных документов и правовых норм, касающихся обязательного информирования и обучения, а также обращения с личными финансами;

- отсутствием информационной поддержки населения в области защиты прав потребителя финансовых услуг;

- низким уровнем материально-технического, кадрового, информационного обеспечения, утвержденных программ и запланированных мероприятий для повышения финансовой грамотности.

Финансовая грамотность - рациональное (разумное) умение распределять денежные средства от источников дохода. Финансово грамотным можно назвать того, кто в пределах ежемесячного совокупного дохода находит возможность обеспечить себя и свою семью необходимыми ресурсами, а также часть средств оставить для сбережения [6].

Обозначим навыки и установки финансово грамотных людей:

1) ведут учет личных фринансов - баланс поступлений (доходов) и трат (расходов);

2) знают, что такое личный финансовый план (ЛФП), умеют его составлять и следовать ему;

3) имеют множественные источники дохода, а не один;

4) расходуют меньше, чем зарабатывают, т. е. живут по средствам, стараются не пользоваться займами и кредитами, а если и прибегают к ним, то для приобретения активов - того имущества, которое приносит им положительный денежный поток и дополнительный доход;

5) имеют резервный денежный фонд, который равен 4-6 месячным расходам, так называемую «подушку безопасности», в случае непредвиденных обстоятельств могут использовать резервные средства;

6) содержат накопления в надежных финансовых учреждениях и преумножают их;

7) знают, что такое страхование, и пользуются им;

8) применяют разные социальные льготы и налоговые вычеты от государства;

9) способны распознать признаки финансовых пирамид и финансового мошенничества.

Стратегия включает положения о необходимости внедрения обучения финансовой грамотности в нашей стране в образовательные учреждения на уровне школы, ссуза, вуза, а также на рабочих местах за счет работодателя. К примеру, в Японии население пользуется популярной системой «Кабеба» - методикой ведения и учета личного и семейного бюджета, которая была разработана еще в XIX в. Использовать данную схему обучают детей с начальной школы. В том числе из-за применения описанной системы в Японии такой высокий уровень жизни.

Финансовая грамотность основана на финансовом планировании. Любой план разрабатывается для того, чтобы можно было добиться нужного результата, и показывает, какие действия необходимо осуществить, чтобы получить желаемое. Для этого человеку следует четко сформулировать жизненные цели [7]. У каждого они свои, и каждый самостоятельно решает, чего он 
хочет в жизни. При этом, на наш взгляд, существуют три универсальные цели, которые подходят любому индивиду.

Первая универсальная цель - это достойное и обеспеченное будущее, т. е. личные накопления и активы, на которые можно жить в старости. Если не позаботиться об этом заранее, человек может рассчитывать только на государственную пенсию.

Вторая цель - жилье. Наличие собственного жилья для большинства граждан России остается сложной проблемой. Жилищный вопрос остро стоит перед населением страны, особенно перед молодежью. Каждый, у кого нет в собственности дома, вынужден его приобретать по рыночной цене разными способами. Если у человека нет денег на приобретение недвижимости, значит, у его семьи не будет жилья.

Третья общая для многих людей цель - это воспитание и обучение детей и помощь в решении их квартирного вопроса. Рождение и воспитание - процесс морально и материально затратный. Детям необходимо получать образование, входить во взрослую жизнь, решать уже свою жилищную проблему, для этого им понадобятся фринансовые ресурсы. Чем раньше родители начнут откладывать часть дохода на обучение и будущее жилье для ребенка, тем больше вероятность того, что они дадут ему достойное образование и снимут жилищный вопрос.

Добиться поставленных целей помогает личный финансовый план - инструмент, основанный на источниках дохода, стоимости цели и времени ее достижения [8].

Таким образом, повышение финансовой грамотности в Российской Федерации с учетом координации работы всех участников экономической деятельности, а также принятие и утверждение Стратегии являются особенно актуальными и обязательными механизмами обеспечения рационального поведения российского общества и, как следствие, повышения уровня жизни отдельно взятого индивида. Все это позволит населению получить необходимые знания и навыки в области финансовой грамотности, увеличить уровень доверия к финансовой и банковской системам, снизить риски в сфере личных финансов, повысить степень благосостояния и укрепить экономическую безопасность страны.

\section{Ссылки:}

1. Цветова Г.В. Повышение финансовой грамотности населения: настоящее и будущее // Экономика и предпринимательство. 2016. № 3, ч. 2. С. 594-598.

2. Национальная стратегия повышения финансовой грамотности 2017-2023 гг. [Электронный ресурс] : проект распоряжения Правительства PФ. URL: https://www.minfin.ru/ru/document/?id_4=118377 (дата обращения: 06.12.2017).

3. Modigliani F. Fluctuations in the Saving-Income: A Problem in Economic Forecasting // Studies in Income and Wealth : Conference on Research in Income and Wealth. N. Y., 1949. P. 369-444.

4. Кузина О.Е. Финансовая грамотность россиян (динамика и перспективы) // Деньги и кредит. 2012. № 1. С. 68-70.

5. Национальная стратегия ...

6. Савенок В.С. Как составить личный фринансовый план и как его реализовать. М., 2011. 246 с

7. Химкатов У.С., Койчуева М.Т. Необходимость повышения финансовой грамотности населения (теоретический аспект) // Вестник Кыргызско-Российского славянского университета. 2015. Т. 15, № 8. С. 174-178.

8. Савенок В.С. Указ. соч.

\section{References:}

Khimkatov, US \& Koychueva, MT 2015, 'The need to increase the financial literacy of the population (a theoretical aspect)', Vestnik Kyrgyzsko-Rossiyskogo slavyanskogo universiteta, vol. 15, no. 8, pp. 174-178, (in Russian).

Kuzin, OE 2012, 'Financial literacy of Russians (dynamics and prospects)', Den'gi i kredit, no. 1, pp. 68-70, (in Russian).

Modigliani, F 1949, 'Fluctuations in the Saving-Income: A Problem in Economic Forecasting', Studies in Income and Wealth: Conference on Research in Income and Wealth, New York, pp. 369-444.

Savenok, VS 2011, How to make a personal financial plan and how to implement it, Moscow, 246 p., (in Russian).

Tsvetova, GV 2016, 'Improving the financial literacy of the population: the present and the future', Ekonomika i predprinimatel'stvo, no. 3, part 2, pp. 594-598, (in Russian). 